\title{
A PERSISTÊNCIA DOS PRECONCEITOS
}

\author{
THE PERSISTENCE OF PREJUDICE
}

Diego Ramos Mileli ${ }^{1}$

Recebido: 10/2017 Aprovado: 05/2017

\begin{abstract}
Resumo: Neste artigo é defendido que 'os iluministas' não poderiam ser capazes de eliminar os preconceitos, como pretendiam, haja vista que atacavam o fenômeno do preconceito onde ele não estava, sendo o entrave no acesso à verdade apenas um efeito colateral do preconceito e não seu elemento central. Independente da possibilidade ou não de se eliminar os preconceitos, a estratégia adotada pelos filósofos desse período estava condenada ao fracasso. Para sustentar esta hipótese, primeiro será extraída uma noção geral do preconceito a partir de autores do período do iluminismo. Em seguida serão estudados seus aspectos a fim de compreender a relação dos preconceitos com a realidade. Por fim se demonstra que o caráter dessa relação é acidental, não podendo o preconceito ser abolido por uma argumentação acerca da verdade das coisas. Este artigo não discute se é possível eliminar os preconceitos, apontando apenas o erro do método dos autores modernos.
\end{abstract}

Palavras-Chave: Preconceito; Iluminismo; Verdade; Afetos; Medo.

\begin{abstract}
This paper argue that 'the Enlightenment' could not be able to eliminate prejudices, as intended, given that they attacked the phenomenon where it was not. The hindrance of access to the truth was only a side-effect of prejudice and not its central element. Regardless of whether is it possible to absolutely eliminate prejudices, their strategy adopted by the philosophers was doomed to failure. To support this hypothesis, we will, first, extract a general notion of prejudice from some modern authors. Then, we will study the aspects of such a conception, in order to find out the relationship of the prejudices with reality. Finally, it will be shown that the character of this relationship is accidental and the prejudice cannot be abolished by any argument about the truth of things. This article doesn't address the question, whether is it possible to eliminate prejudices, but focuses only on the mistake of the modern author's method.
\end{abstract}

Key-words: Prejudice; Enlightenment; Truth; Affects; Fear.

\section{Introdução}

No âmbito desse estudo se tem por objetivo investigar por quais motivos os iluministas não poderiam ser bem-sucedidos em sua luta contra os preconceitos. Os iluministas foram surpreendidos pela enorme dificuldade em se desfazer os preconceitos dos outros. Esse trabalho se dedica, então, não à discussão sobre se os preconceitos são de fato elimináveis ou não. A investigação concerne à persistência dos preconceitos e à falha dos iluministas no que se refere à estratégia adotada para eliminação dos preconceitos. Sendo assim, a fim de compreender a persistência dos preconceitos apesar das tentativas de superá-los, temos que nos perguntar, entre outros: Qual o motivo pelo qual alguém se nega a reconhecer 'a verdade'? Por que alguém mantém a opinião mesmo quando foi claramente demonstrado que os fatos são outros? De onde vem a persistência dos preconceitos apesar da contradição destes e da existência de explicações mais adequadas para os mesmos fenômenos?

O tema do preconceito fora, no período do iluminismo, de extrema

\footnotetext{
${ }^{1}$ Bacharel em Filosofia pela UFRJ e Mestrando pela Universität Hamburg - UHH.

Problemata: R. Intern. Fil. V. 8. n. 2 (2017), p. 19-35 ISSN 2236-8612 doi:http://dx.doi.org/10.7443/problemata.v8i2.31190
} 
importância para a superação da tradição escolástica e da questão da autoridade, a qual era considerada um empecilho no acesso à verdade. Para tais autores, ao se colocar em questão a tradição escolástica e a autoridade se abriria espaço para uma crítica com base na 'razão', e consequentemente para 0 afastamento das 'falsas teses' que eram tomadas como verdade e fundamentavam o conhecimento de até então. Atualmente o problema dos preconceitos reaparece, mas com outro foco, a saber: $O$ preconceito social intergrupos. Hoje em dia, ao se ouvir a palavra 'preconceito' se pensa no crescimento dos movimentos xenofóbicos, na islamofobia, na homofobia, no machismo e nos atos perpetrados pelo grupo denominado Estado Islâmico - El - etc. Em décadas passadas se teria provavelmente pensado nas leis racistas dos Estados Unidos, no Apartheid sulafricano ou no sistema de castas indiano. Apesar das variações na perspectiva notáveis nos trabalhos interdisciplinares dos séculos XX e XXI, o problema ainda é significativo, mesmo no nível epistêmico. Não é possível compreender o atual fenômeno do preconceito em contexto social sem atentar para a questão de o que são preconceitos, afinal. Qual influência eles exercem sobre o nosso conhecimento do mundo? Ou, relacionado à nossa questão: Em que reside a persistência dos preconceitos, a qual se fez visível na tentativa de superação dos preconceitos?

Etimologicamente a palavra 'preconceito' é em grande parte dos idiomas europeus ocidentais um juízo antecipado. Em espanhol prejuício, em inglês, prejudice, em francês préjugé, em italiano, pregiudizio, em alemão, Vorurteil, e assim por diante. Todas essas palavras são compostas pelo prefixo correspondente a 'pré-' e pelo substantivo 'juízo'. Embora seja curioso o fato de em português ter sido utilizado o substantivo 'conceito' em vez de 'juízo', não cabe aqui uma pesquisa sobre o porquê desta diferença. A palavra conceito possui entre seus significados também a ideia de juízo ${ }^{1}$. Sendo assim, prosseguiremos sem dar especial relevância a esta peculiaridade da língua portuguesa. Retornando à palavra, é prudente fazer alguns questionamentos. Por exemplo: O que significa o prefixo 'pré-' nesse contexto? Deverá ele ser entendido temporal ou espacialmente? O preconceito como conceito prévio requer de fato a ausência de experiência? Quais são as especificidades que caracterizam algo como preconceito? Por que eles teriam que ser abandonados? Por que, como dito acima, ele não são imediatamente afastados?

No intuito de responder essas e outras questões, o trabalho será dividido da seguinte forma: Primeiramente serão analisadas as contribuições de diversos autores ao tema 'preconceito', a fim de extrair daí um conceito geral de preconceito. O foco nesta parte será sobre o iluminismo, já que este período é o mais significativo no que se refere ao debate geral acerca do preconceito. Após a identificação das características constitutivas do preconceito, os 
questionamentos serão então direcionados à resistência a abandonar os preconceitos. Nesta seção se procederá primeiro ao questionamento de quais características do preconceito seriam responsáveis por essa dificuldade em superá-los. Por fim, procederemos à investigação do porquê de estas características provocarem a persistência dos preconceitos. Adicionalmente, há que se responder qual a relação entre a tal propriedade, responsável pela manutenção do preconceito mesmo ante fortes indícios que o contradizem, e o mundo, de forma que se possa concluir sobre as circunstâncias que viabilizam essa persistência. Ou seja, por que os iluministas se depararam com essa dificuldade e por que as 'evidências da realidade' não foram capazes de vencer os preconceitos.

\section{Os preconceitos no Iluminismo}

O tema 'preconceito' é um tema da filosofia moderna. O que não significa que ele não tenha sido abordado anteriormente ou que não houvesse preconceito, mas foi no período do iluminismo que ele foi intensivamente apresentado e analisado como problema filosófico, embora na filosofia antiga, em Epicuro, por exemplo, o preconceito já tenha sido objeto de consideração. De acordo com o filósofo, os preconceitos seriam uma ideia geral e uma ferramenta positiva, concebida a partir da repetição e acúmulo de experiência, por meio da qual se poderia orientar e antecipar a reposta a situações já vividas (Cf. Morana \& Oudin, 2010, 21). No lluminismo, por outro lado, o preconceito foi tido por negativo - uma barreira para o reconhecimento da verdade pela razão, a qual teria inclusive que ser eliminada. Para compreender melhor o que são os preconceitos e porque eles deveriam ser desconstruídos, temos que lançar o olhar sobre as interpretações de diversos autores que se dedicaram ao tema.

No século XVII, Francis Bacon escreveu seu Novum Organum, no qual a problemática acerca do preconceito aparece, a saber: em sua teoria dos ídolos. Segundo Bacon existiriam quatro tipos de Ídolos: Idola Tribus, Idola Specus, Idola Fori e Idola Theatri. Resumidamente, o Ídola Tribus é um preconceito embora ele não utilize essa palavra - que se encontra seja na natureza humana, seja em sua linhagem ou na espécie humana. O Ídola Specus seria um preconceito individual, o qual surge seja por suas características pessoais ou por meio da educação. O Ídola Fiori, por sua vez, é constituído a partir da interação humana. Incluem-se aí as palavras, que, se utilizadas incorretamente prejudicam o entendimento e conduzem a mal-entendidos. Por fim, Bacon chama de Idola Theatri, aquele que criado pelas doutrinas filosóficas ou pelas deduções erradas ou confusas (Cf. Bacon, 1620, I. XLI - XLIV). O ponto em comum entre eles é o 
fato de serem ideias inúteis que distorcem a realidade e, com isso, atrapalham o acesso à verdade (Cf. Bacon, 1620, I. XXIII, XXXVIII). Em vista disso, ele conclui que os ídolos devem ser abolidos, a fim de libertar o intelecto (Cf. Bacon, 1620, I. LXVIII).

Entretanto, libertar-se de preconceitos não é uma tarefa fácil. A cada nova vivência ressurgem essas falsas noções, tanto em razão da defesa do pensamento anterior, tanto devido à representação previamente construída no que diz respeito ao objeto (Cf. Bacon, 1620, I. CXV). Há que se notar aqui que esta permanece em aberto de onde vem essa defesa e porque ela conduz ao preconceito em vez de a opinião se modificar a partir da experiência. Bacon entende que a dedução equivocada é a principal origem das falsas noções. Tendo em vista que o intelecto não deve ser conduzido pela retórica, há que se proceder à 'verdadeira indução'. Para isso as impressões sensoriais e as conclusões deduzidas a partir delas teriam que ser suspendidas, a fim de se construir noções estritas e bem definidas por meio da cuidadosa dissecação e anatomia do mundo (Cf. Bacon, 1620, I. XL, LXIX, CXXIV).

Até então é possível afirmar que os preconceitos surgem em razão da natureza humana, da educação, dos mal-entendidos e das deduções equivocadas. Partindo do princípio de que os ídolos surgem por meio da educação e de deduções falhas, as noções equivocadas podem ser transmitidas através das tradições, de modo que os seus danos se espalham. As noções daí originadas distorcem a realidade e constituem obstáculo no acesso à verdade. Em outras palavras, não se critica a tradição. Em consequência, o falso é aceito como verdade e assim ensinado. Além disso, haja vista o cuidado com as opiniões dominantes, esses preconceitos seriam difíceis de se combater. Os seres humanos não estão dispostos a abandonar uma noção já tradicional. $O$ caminho para noções estritas e definidas seria a análise cuidadosa e racional, livre da enganação das impressões sensoriais. Somente assim se poderia superar a resistência que essas noções exercem. As condições para a verdade apresentadas por Bacon nos remetem ao 'claro e distinto' cartesiano como requisito para o conhecimento da verdade; em especial na suspeição com relação aos sentidos.

Dada a resistência das noções embasadas em explicações falsas, Réne Descartes vai mais adiante e busca afastar todas as suas opiniões anteriores e proceder à dúvida metódica, com o objetivo de assim encontrar ao menos uma verdade de onde possa deduzir um conhecimento de base sólida. Assim começa suas meditações. O motivo para a adoção de tal método reside na constatação de que diversas ideias falsas seriam tomadas por verdade e todo o conhecimento proveniente delas teria um caráter no mínimo duvidoso. Ele se concentra então nos princípios sobre os quais residem suas antigas ideias, a fim de construir um 
conhecimento livre de preconceitos. Esses conhecimentos não poderiam se basear nos sentidos, haja vista que estes seriam por vezes enganadores, e, por isso, não ofereceriam uma boa base. O fundamento deveria ser uma verdade inegável, para a qual somente o intelecto seria adequado. Tal como Arquimedes, o qual afirmava precisar de apenas um ponto fixo para poder mover o mundo, Descartes busca por algo que seja certo e indubitável. Sua verdade é: Eu sou, eu existo (Cf. Descartes, 1641). Ao fim da segunda meditação Descartes reconhece, porém, a dificuldade em abolir os preconceitos (Cf. Descartes, 1641).

Partindo da aplicação do método da dúvida nas primeira e segunda meditações, observa-se que o objetivo de Descartes não foi somente suspender as ideias falsas, mas todas elas. A dúvida é direcionada a tudo que não é descoberto a partir da cuidadosa análise da razão liberta das impressões sensoriais. Pode-se, portanto, afirmar que toda informação de segunda mão, tal como as informações obtidas por meio das apreensões dos sentidos, são duvidosas e por isso devem ser verificadas pela razão.

A rejeição às informações obtidas em segunda mão traz consigo a questão da autoridade, cujo significado Christian Thomasius e Condorcet destacaram. Thomasius declara a autoridade como altamente prejudicial e raiz dos equívocos em geral, a qual deve ser deixada de lado para se poder conhecer a verdade (Cf. Thomasius, 1691/2010, 78). Haja vista que o governo e os padres, entre outros, incentivam a criação e manutenção de preconceitos por meio da educação e das leis, Condorcet os declara "inimigos da razão e opressores da liberdade2" (Cf. Condorcet, 1794/2010, 104). Essa discussão destaca em todo caso que algo não tem necessariamente que ser falso para ser preconceito, já que os alvos são também a autoridade e os conhecimentos de segunda mão. Além disso, ressalta-se a mesma conclusão à qual Bacon chegou, ou seja, que os preconceitos são ensinados por meio da tradição e da autoridade. Nesse sentido, ambos, tradição e autoridade, perdem o seu poder, haja vista que agora as informações que vêm destes meios precisam ser verificadas. Essa verificação pela razão nos remete à exigência kantiana do Selbstdenken, algo como "pensar por si mesmo". Antes disso, porém, analisemos primeiramente John Locke, para seguir uma linha temporal, de forma a apresentar mais precisamente 0 desenvolvimento da questão do preconceito $^{3}$.

Locke tece críticas abertas ao preconceito em sua obra Conduct of the Undestanding, muito embora anteriormente ele já o tivesse indiretamente criticado quando escreve sobre o entusiasmo. Que os preconceitos devam ser abolidos e que eles são a causa de incerteza e equívoco não é colocado em questão por Locke. Como Descartes ele destaca que as próprias opiniões devem ser minuciosamente postos à prova, a fim de descobrir os próprios preconceitos e com isso poder combatê-los. Os preconceitos são também considerados como 
algo que é originado por meio da educação, tradição, do partido etc. O que é ensinado é aceito como verdade indiscutível. Esse tipo de máxima que não é colocada em questão age como impedimento na busca pela verdade e pelo conhecimento.

Em Locke é igualmente destacada a dificuldade de se desconstruir os preconceitos. Em sua teoria isso é não somente um fato meramente mencionado, um resultado observado, mas uma característica essencial aos preconceitos. Os preconceitos são reconhecidos pelo seu persistir em uma opinião. A persistência é identificada quando argumentos contrários ou não são levados em consideração ou quando objeções já são antecipadamente rejeitadas. Ou seja, eles são pontos de vista não verificados, mas tomados como verdade. Eles são verdadeiros e sua verdade não está em questão. Esta seria a principal característica pela qual se permite identificar o preconceito.

Em sintonia com Descartes e Bacon, Locke afirma que a prescrição de opiniões e conhecimento pelas autoridades é um caminho que corrompe a faculdade de julgar. A solução contra os preconceitos seria a indiferença e a verificação das próprias interpretações. Assim se poderia encontrar a verdade (Cf. Locke, 1706/1881, 29 - 36). O conhecimento deve ser certificado por provas e evidências. Nesta função a razão desempenha o papel mais importante. Ela é a última instância para a certificação da verdade. Aqui seriam os preconceitos não somente falsos como também não-racionais. Estes últimos aspectos merecem uma explicação um pouco mais apurada. Por um lado, alguém poderia se portar racionalmente e mesmo assim se equivocar, o que seria, por exemplo, o caso de se chegar a um resultado errado após um cálculo. Mesmo que alguém conheça as regras da aritmética e as queira seguir, poderia ainda assim alcançar um resultado errado. Por outro lado, é possível que alguém chegue por acaso a um resultado correto, ainda que não proceda de acordo com os procedimentos racionais adequados. Neste caso se faz a observação correta, mas a explicação para ela é errada. Um exemplo possível seria o de um pai que prepara uma massa de pizza quando um ovo rola da pia e ameaça cair ao cão. Ele chama seu filho para que ele segure o ovo. A criança, curiosa, pergunta ao pai porque o ovo cai. Ele responde que o demônio quer roubar tudo da Terra para o inferno. Por isso todas as coisas se dirigiriam ao chão quando se está desatento. Embora ele saiba que na Terra todos os corpos pesados tendem ao chão, sua explicação não seria racional. A realidade é distorcida, apesar do resultado correto. Sem a luz da razão seria, então, impossível conhecer a verdade (Cf. Locke, 1689).

Immanuel Kant resume em sua exigência de 'pensar por si mesmo' a característica dos preconceitos destacadas por Locke e Descartes como conhecimento de segunda mão e inverificados. O conhecimento é alcançado pela utilização da razão pelo pensar. O Selbstdenken é a máxima do 
entendimento e do pensar livre de preconceitos. No mesmo sentido que Bacon e Descartes, surge a verdade nos pensamentos apenas após a suspensão dos sentidos (Cf. Kant, 1790, § 40). O pensar por si mesmo traz consigo a responsabilidade que a liberdade exige e a qual muitos não estão preparados em assumir. Adotar e repetir a opinião de autoridades é cômodo. Para Kant essa postura de 'menoridade' [Unmündigkeit] é culpa daquele que se coloca nessa posição, na medida em que cada um tem a possibilidade de abandonar os preconceitos ao decidir pensar por si mesmo (Kant, 1784/2010, 9). Entretanto, pensar por si mesmo é apresentado pelas autoridades como um perigo, no intuito de desencorajar as pessoas da sua maioridade intelectual (Kant, 1784/2010, 10).

Após o delineamento deste panorama e apesar das divergências entre os autores, pode-se afirmar que o preconceito no período do iluminismo é fundamentalmente definido pelas seguintes características. O preconceito é uma ideia/opinião/noção/conceito que (1) distorce a realidade, (2) ou porque é falsa, (3) ou por ser de segunda mão, (4) e não ser verificada pela razão, e (5) na qual se persiste mesmo sem ter razão para isso. Por fim, (6) o prefixo 'pré' no preconceito deve ser tomado em conta, do contrário seria apenas algo como um juízo falso por teimosia. Esse 'previamente' que caracteriza o preconceito não significa necessariamente que se trata de um juízo anterior a qualquer experiência. Com isso se destaca que mesmo que o juízo se baseie em experiências, o ponto é que ele serve como modelo de interpretação para eventos similares no futuro, antes da análise do caso particular. Em outras palavras, mesmo que alguém tenha preconceito contra negros após ter sido assaltado por uma pessoa de pele negra, constitui-se preconceito na medida em que a experiência constrói um modelo de interpretação que é aplicado previamente ao contato com qualquer outra pessoa negra. O conhecimento da verdade é prejudicado por esse modelo. $O$ contato com todas as pessoas negras é distorcido por essa vivência que originou o modelo de interpretação.

Os preconceitos que não são falsos, já que nem todos os autores requerem que o conhecimento seja falso para ser preconceituoso, são englobados pelo ponto 3. A construção 'ou... ou...' cuida primeiramente para que algo seja preconceito tanto quando é correto, mas provém de segunda mão e não é verificado, o que faria dele sem base, quanto, em segundo lugar, quando é falso, mas embasado nas próprias experiências e raciocínios, quanto ainda, em terceiro lugar, quando algo é tanto falso quanto de segunda mão. Não basta, porém, que algo seja falso para que seja um preconceito. A persistência é essencial ao preconceito. Cumpre ressaltar que a persistência injustificada de um preconceito sempre distorce a realidade. Não havendo motivo algum que sustente o juízo, igualmente não haverá motivo que o altere. O juízo não se alterará em consequência de uma mudança no mundo. Esse juízo prévio pode 
ser uma explicação falsa, como no exemplo do pai e seu filho. Essas distorções são solidificadas e fortificadas pelo preconceito.

Após essas considerações resta claro que cada autor destacou o enorme obstáculo encontrado na tentativa de se abolir os preconceitos. Há vários caminhos de se analisar este problema. Contudo, aqui nos interessa não o caminho que ataca a possibilidade ou necessidade de eliminar os preconceitos, mas o caminho que se volta à persistência dos preconceitos nos seres humanos apesar da demonstração das contradições e análise das justificativas, o que provaria a falsidade dos preconceitos. Por que se reluta em abandonar os preconceitos e aceitar a realidade dos argumentos e justificativas que desconstroem os preconceitos? De onde vem a teimosia, apesar dos claramente falsos ou no mínimo extremamente frágeis motivos que sustentam um preconceito? Isso é o que será investigado na seção a seguir.

\section{A Persistência dos Preconceitos}

Agora, após ter sido traçado um panorama sobre o preconceito e seu percurso como objeto filosófico, dispomos dos fundamentos para proceder à análise sobre sua persistência. O preconceito é um juízo persistente, ou infundado, ou falso ou de segunda-mão, que distorce a realidade. Se a realidade é distorcida, nos deparamos com o seguinte problema: Sendo a realidade modificada, o preconceito não pode simplesmente ser superado pela experiência ou argumentos, pois o preconceituoso interpreta a realidade de forma diferente de modo a preservar seu preconceito. O simples desenvolver de uma análise que demonstre os motivos pelos quais o juízo preconceituoso deveria ser abandonado não está em condições de vencer o preconceito. Que os preconceitos não podem ser vencidos por argumentos acerca da verdade foi 0 que os iluministas, engajados no combate ao preconceito, experienciaram, muito embora acreditassem no contrário. Por que alguém mantém o preconceito apesar das claras contradições de seu juízo anterior? Antes de responder a esta questão, temos que analisar se os preconceitos de fato se comportam de maneira persistente.

Tomemos então como exemplo um preconceito em contexto social, já que estamos mais acostumados a lidar com estes. Exemplo 1: Uma pessoa acha que os refugiados são aproveitadores que querem simplesmente sugar o sistema social sem trabalhar ou se integrar. Essa pessoa encontra refugiados que trabalham no caixa dos supermercados. Alguns de seus amigos são inclusive filhos de refugiados da última geração. Até mesmo seu tio-avô se refugiou nos Estados Unidos quando da Segunda Guerra. Ela desmerece esses fatos 
completamente ao afirmar que aqueles que ela conhece são meras exceções. Seu juízo não corresponde à realidade que se apresenta, mesmo assim ela o mantém. Exemplo 2: Outra pessoa pensa que gays são promíscuos. Ela sabe que seu irmão, hétero, se encontra concomitantemente com mais de uma mulher. Por outro lado, seus vizinhos são um casal gay que vive junto há 15 anos. Seu primo de segundo grau também é gay e em sua vida inteira teve apenas dois namorados. Mesmo assim, ela os considera como exceções. Desta forma ela justifica seu juízo de que gays são imorais e reprováveis, mesmo que seu primo e seus vizinhos sejam fiéis e tenham até mesmo uma boa relação com ela. Outra vez nos deparamos com uma reinterpretação do mundo, de forma a conservar os preconceitos. Tais fatos são numerosos na sociedade, de modo que possivelmente cada pessoa conhece um exemplo semelhante. Além disso, estes são exemplos incontroversos de preconceito. Ambos são modelos de interpretação contraditos pela experiência e que mesmo assim prosseguem considerados como válidos. Haja vista que os juízos não são comprovados pela experiência, devem proceder de outra fonte - de segunda-mão - sem ter sido verificados pelo receptor da informação. Com isso é possível assegurar que a persistência de fato se encontra presente no preconceito. Conclusão essa que é comprovada também por cientistas sociais (Cf. KLEG, 1993, 113-134 e ALLPORT, 1958, 17-27).

A isso se poderia objetar que cientistas também persistem em suas teorias. Mesmo que haja contradições nelas, eles não as deixam de lado (Cf. Dorschel, 2001, 141). Fosse de fato assim, seria um problema dos cientistas, não da filosofia do preconceito. Pode-se afirmar que ou os pesquisadores têm preconceitos, caso se portem assim, ou que o preconceito não devesse ser abolido nem seja contrário à ciência e ao conhecimento. Há, porém, outra resposta possível. Caso os pesquisadores não abram mão de sua teoria, mesmo assim pode ser que eles não tenham preconceito, apesar dos dados conflitantes. A explicação para este caso seria o juízo se tratar de inferência da melhor explicação (Inference to the best explanation - IBE). Ou seja, eles analisaram todas as outras explicações possíveis e concluíram que, apesar das falhas encontradas em sua própria teoria, ainda assim ela se apresenta como a melhor explicação encontrada até o momento para dar conta do fenômeno. Nessa hipótese não haveria preconceito. No preconceito mantém-se o juízo embora haja uma explicação racional mais consistente, cuja probabilidade ou retitude são avaliáveis e permanecem abertas à prova do contrário.

Depois de ter sido comprovada a persistência dos preconceitos, resta ainda responder quais são suas raízes. A primeira pista no caminho para encontrar a origem dessa persistência do preconceito reside na obra de Locke. Acima, ao abordarmos a questão do preconceito em sua obra, mencionamos 
que ele fala sobre o entusiasmo. Esse seria um possível motivo pelo qual alguém preserva seu juízo infundado. É de se supor que o filósofo tivesse em mente o sentido etimológico da palavra. A palavra entusiasmo vem do grego $\varepsilon v \theta o u \sigma ı \alpha \sigma \mu o ́ s-e$ é composta do prefixo $\varepsilon v$ (em) e dos substantivos $\theta \varepsilon o ́ s$ (Deus)

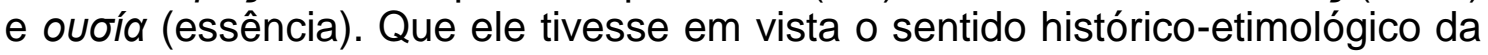
palavra se deixa provar por diversas menções ao problema da 'revelação' ao longo do mesmo texto. Aqueles que acreditam estar 'na essência de Deus' não precisam de qualquer outro motivo para justificar seu juízo. Eles alcançaram a essência de Deus. Os outros necessitam por não terem alcançado a verdade através da vivência da comunhão com Deus. Entretanto, o debate concernente à revelação não nos interessa aqui. Em todo caso, como conclusão dessa discussão, Locke afirma que a última palavra é da razão. Ela deve analisar as revelações e justificá-las e, se for o caso, rejeitá-las como falsas. Haja vista que o entusiasmo é algo que é sentido, nos deparamos com uma contraposição entre afetos e razão. Locke escreve que "Quando alguém diz que vê ou sente, ninguém pode convencê-lo do contrário4" (Cf. Locke, 1689). Com isso, sugerese que os afetos estão por trás da persistência. Quem sente algo não precisa explicar porque aquilo que sente é verdade. Sente-se que é verdade. A evidência para isso que se sente ser verdadeiro é exclusivamente o forte sentimento. Locke critica que este sentimento não é um amor pela verdade, mas por algo outro. Visto dessa forma, o problema do preconceito não seria então a sua afetividade, mas o fato de que o afeto do conhecimento seria tão-somente o amor à verdade.

Em Locke, como já mencionado, os preconceitos devem ser superados pela indiferença e cuidadosa verificação das próprias ideias. Há que se esclarecer, no entanto, como essas duas estratégias atuam no combate aos preconceitos. A indiferença age para impedir que a posição que se tem seja amada, bem como para impedir que se deseje que ela seja verdadeira. $\mathrm{Na}$ hipótese de se desejar que ela se prove verdadeira podem ser ignorados indícios que a contradizem. Nesse caso se quereria que algo fosse comprovado como verdade, em vez de se querer descobrir a verdade. Esse problema seria contornado pelo método da indiferença. A verificação, por sua vez, deve ser conduzida pela assumpção do próprio pensamento como falso e inútil para experimentar as outras opiniões e os argumentos contrários a ele. Pela investigação de diversas alternativas se verificaria racionalmente a própria interpretação (Cf. LOCKE, 1689).

O amor à verdade deveria ser o único guia na busca pelo conhecimento. Quando ao invés disso a opinião é o objeto do amor, nos depararíamos então com o preconceito, pois tal amor impediria que a verdade fosse descoberta, caso a opinião se mostre falsa. A força da posição tomada deveria ser tão grande quanto o grau de segurança que as evidências propiciam. $O$ amor ou 0 
entusiasmo à opinião abrem o caminho para o infundado - nesse sentido, preconceituoso - ponto de vista (Cf. LOCKE, 1689). Devido à opinião afetada, os preconceitos seriam difíceis de se superar, pois se perderia o objeto do afeto. Por trás do entusiasmo e do amor ao próprio ponto de vista injustificado se esconde o desejo de não ter seu posicionamento questionado, em vez do desejo pela verdade (Cf. LOCKE, 1706/1881, 29 - 36).

Aqui aparece um aspecto do preconceito que pode ser melhor esclarecido com a análise de Kant. No preconceito reside o desejo de não perder o objeto de seu amor, ou seja, de deixar a opinião sem ser questionada. Entra em cena o papel das atitudes proposicionais na questão do preconceito.

Kant interpreta a minoridade representada pela rejeição ao pensar por si mesmo como 'culpa própria' [Selbstschuld] (Cf. KANT, 1784/2010, 9). Visto que o pensar por si mesmo representa um perigo, seria preferido aceitar a autoridade dos outros (Cf. Kant, 1784/2010, 10). Ao se debruçar atentamente sobre esses dois pontos, se sobressai que os preconceitos não são meros juízos falsos ou inverificados, mas interligados com seus respectivos afetos e atitudes. Partindose do princípio de que a menoridade intelectual é culpa do próprio sujeito que não quer se libertar pelo pensar por si mesmo, deduz-se que o sujeito quer a menoridade. Em outras palavras, quer-se ter preconceitos, pois é mais cômodo e seguro que pensar. Quer-se-o, porém, não por um simples e racional querer livre, mas pelo medo ante o perigo que pensar por si mesmo representa. Neste sentido resta claro por qual motivo o juízo de segunda-mão - ou seja, o preconceito: o juízo que não é construído por si mesmo - é aceito. É uma posição tomada arbitrariamente. Alguém permanece nesta menoridade porque teme algo e não quer confrontar o perigo. Tal como Locke, o qual o situa o amor e o entusiasmo como indício de preconceito, Kant coloca o medo à liberdade, se associamos a maioridade intelectual à liberdade. A persistência resulta em uma reinterpretação do mundo, a fim de manter a posição anterior, tradicional e irresponsável. Irresponsável no sentido de que não se assume a responsabilidade que advém da liberdade, no caso, de pensar por si mesmo. Assim, as justificativas para o juízo não podem estar relacionadas à coisa julgada. Todavia, o juízo é racionalizado, o que naturalmente não é nenhuma melhora na posição do preconceito. Erich From destaca: "As racionalizações não são meios apropriados para penetrar na realidade, mas somente uma tentativa post factum de harmonizar o próprio desejo com a realidade disponível ${ }^{5}$ " (Cf. FROMM, 1941/2013, 144). Ou seja, a racionalização pode ser da mesma forma uma consolidação do preconceito. Em todo caso, isso não é nenhuma objeção à concepção de preconceito desenhada pelos iluministas, pois aqueles autores também ressaltam que falsos pontos de vista podem ser um preconceito, ainda que justificados com aparência racional, como no caso dos preconceitos 
transmitidos pela educação. Se algo é falso não quer dizer que é irracional, mas que pode ter havido alguma falha no processo de compreensão. O desejo, na formulação de Fromm, chama a atenção. Novamente é ressaltado o aspecto afetivo que suporta um juízo que distorce a realidade.

Assim é percebido que a persistência do preconceito está conectada ao posicionamento fortemente afetado. Além disso, a formulação racional da atitude proposicional expressa o afeto que está por trás do preconceito. Dito de outra forma, pode haver uma argumentação racional que sustente os preconceitos. Contudo, a racionalização funciona como uma reinterpretação do mundo para satisfazer um desejo: o de manter a opinião. Com ajuda dos seguintes exemplos talvez se possa proceder a uma melhor elucidação.

Tomemos outra vez a pessoa do preconceito com relação aos refugiados do primeiro exemplo. Ele afirma que os refugiados querem se aproveitar do sistema social. Seu modo de pensar pode ser formulado da seguinte forma: Ela é contra que os refugiados vão à Europa, pois ele acredita que eles querem se aproveitar do sistema social. Além disso, ele teme que, caso ele necessite do auxílio do sistema social, ele, por culpa dos refugiados, não o possa receber. Seu preconceito está baseado em uma imaginação de uma situação futura e em um medo. Para manter essa apresentação da situação futura ele reinterpreta o mundo, pois ele quer se proteger de um perigo, a saber: a exploração à míngua do sistema social. Assim, ele acredita que se os refugiados forem excluídos da Europa o sistema social estará assegurado. Ele crê que o melhor meio, ou o mais fácil, de garantir o funcionamento do sistema social é impedindo a entrada de refugiados. Seu preconceito tem, com isso, um motivo e um objetivo. Haja vista que esse motivo e objetivo não são atingidos pelos argumentos de que os refugiados não são um grupo homogêneo que possa ser julgado igualmente, ou que os motivos não correspondem à verdade, permanece o preconceito.

A pessoa do segundo exemplo pensa que gays são promíscuos e, por isso, detestáveis. Ela crê que eles são detestáveis, pois ela considera a promiscuidade imoral. Ela deseja a moral e teme a imoralidade. A imoralidade ameaçaria a integridade da sociedade. A teórica promiscuidade dos gays é criada como ameaça somente após o medo ante a desintegração social causada pelo imoral. Ela detesta os gays, pois ela acredita que eles são promíscuos e teme os danos provocados pela imoralidade.

A conexão entre o afeto e preconceito fora também identificada pelo psicólogo Gordon W. Allport. O autor distingue entre prejudgment e prejudice, que utilizaremos aqui respectivamente como preconcepção e preconceito. A preconcepção carece do afeto e, com isso, da persistência. As preconcepções seriam, então, as opiniões que se deixam alterar quando fatos e argumentos a desconstroem. Ela permanece em aberto e com isso não constitui um empecilho 
à verdade. As preconcepções se tornam preconceito a partir do momento em que novos conhecimentos não são capazes de corrigi-las. Em resumo, Allport afirma que, "Assim, a diferença entre preconcepções ordinárias e preconceito é que se pode discutir e retificar uma preconcepção sem resistência emotiva." ${ }^{6}$ (Cf. ALLPORT, 1958, 9-10.) A distinção entre preconcepção e preconceito é importante para evitar equívocos na análise do problema e para responder à nossa próxima questão.

Já fora esclarecido que a persistência age em razão dos fortes afetos que residem no preconceito. Entretanto, continua sem estar claro por qual motivo eles constituíram uma barreira na visão dos iluministas. Os afetos não poderiam ser desfeitos quando a verdade fosse minuciosamente e argumentativamente demonstrada? A análise de Heidegger sobre o medo pode nos auxiliar na compreensão desta questão. Ele aponta que aquilo que é temido como ameaça é constituído pelo próprio temor.

Não é primeiramente algo que é constatado como um mal futuro (malum futurum) e então temido. Mas também não é o temer que constata primeiro o que se aproxima, mas o descobre antes em sua temeridade. E, temendo, pode então o temer, expressamente olhando adiante, fazer claro para si o temível. O olhar ao redor vê o temível porque ele se encontra na disposição do temor. (Cf. HEIDEGGER, 1926/1967: 141.) $)^{7}$

Destaca-se, portanto, que o temor não surge do temível, senão que o temor 'inventa' o temível a fim de expressar e tornar claro o temor. Mesmo que a realidade fosse - ou seja - outra, o temor permanece intocado e o temível e projetado em outro objeto. Além disso, o motivo para o medo é um mal futuro. Consequentemente o mal não pode ser desconstruído pela negação dos fatos e verdades concernentes ao atual 'pois', o qual é o motivo alegado para o preconceito, já que o motivo não está lá. Ele se aproxima. Ou seja, os preconceitos não se alimentam dos fatos do mundo, mas da ameaça futura, a qual no futuro virá, em tese, a constituir um perigo verdadeiro. Aquilo que acontece é reinterpretado em benefício do preconceito. O medo não precisa ser real. Ele se projeta sobre a realidade depois que já foi sentido. Mesmo aquilo que não existe pode ser temido. Fantasmas, demônios, entre outros, são exemplos de que o medo pode ser provocado por aquilo que não existe. Isso faz inclusive mais difícil combatê-lo, já que a inexistência de algo não pode ser provada. Então o perigo se mantém ali, à espreita. E com isso, o medo, que continua a ser sentido. O medo tem sempre diante de si um temível no futuro que não pode ser negado pelo presente. Assim se pode compreender a reinterpretação do mundo. O motivo alegado para o preconceito corporifica a causa do afeto, embora o objeto seja escolhido apenas após o afeto ser sentido e racionalizado. Ainda que se mostre falso o motivo - que refugiados contribuem 
para o sistema social na medida em que reduzem a idade das forças produtivas -, mesmo assim não se altera o afeto. Se o motivo alegado puder ser visto como causa do afeto, este deveria se alterar, caso o motivo racionalizado se mostre falso. Mas não é o que acontece. Como Locke ressaltou: Sente-se-o. Com isso é rejeitada a falsidade do motivo alegado.

O motivo da dificuldade dos iluministas em afastar os preconceitos é assim aclarado. Os sentimentos não necessitam da relação com a realidade para serem sentidos. O objeto relacionado ao sentimento é procurado somente após o sentimento. O objeto do sentimento é criado pelo sentimento, e não o contrário. Ou seja, os afetos escondidos no preconceito não necessitam nem da verdade nem do conhecimento da verdade. Os iluministas buscaram abolir os preconceitos argumentando que se deve pensar racionalmente para poder conhecer a verdade. Mas o desejo que se esconde por trás dos preconceitos é outro, e não o desejo pela descoberta da verdade. Por isso, suas argumentações e estratégias não encontraram eco nos pensamentos preconceituosos. Os desejos intrincados nos preconceitos não correspondem ao conhecimento da verdade. Além disso, seus temores não nascem de uma interpretação equivocada do mundo. Ao contrário, por temer, interpretam o mundo de forma a justificar o temor que sentem. Os iluministas não lograram alcançar a raiz de tais pensamentos preconceituosos. A estratégia de reinterpretação é o que concede segurança e consistência aparente aos preconceitos. Então o preconceito se justifica ante a contradição no mundo pelo argumento de que pode haver exceções à sua interpretação, mas isso não quereria dizer que ela é falsa. Afinal, seu medo persiste e precisa de explicação.

\section{Conclusões}

Este trabalho não tem a pretensão de resolver todos os problemas relacionados ao preconceito. Fora do espectro deste trabalho pairam outras questões como: Qual a melhor definição para o preconceito (já que aqui foi analisada a questão em alguns autores do iluminismo)? Quais os afetos que estão ligados ou podem estar ligados aos preconceitos? Não poderiam as preconcepções ter também outras formas de afeto que não gerariam preconceito? O intuito aqui - e espero que me tenha sido possível aclarar - foi o de mostrar quais são os motivos com os quais os iluministas se depararam na sua empreitada pela abolição dos preconceitos e que lhes constituíram obstáculo, apesar de crerem apresentar a verdade, a qual deveria eliminar todos os erros e preconceitos. Tampouco tratou-se aqui da possibilidade ou não de se eliminar todos os preconceitos. $O$ foco do trabalho foi o de encontrar o motivo 
para a resistência à superação dos preconceitos, o qual foi relatado por todos os autores iluministas citados na primeira seção. Os preconceitos não são abandonados ante os argumentos pois a relação com o real é um aspecto não essencial dos preconceitos, de modo que a análise da realidade não é capaz de desfazer os afetos que fundamentam o preconceito, já que os afetos vêm antes da realidade. Como disse Horkheimer, "argumentar contra a rigidez dos preconceitos é vão" (Cf. HORKHEIMER, 1962, 9). Ou seja, a estratégia dos iluministas errou seu alvo.

Com este trabalho podem ser tiradas quatro importantes conclusões, as quais eu retomo e esclareço brevemente:

1) Para os inimigos dos preconceitos no período do iluminismo o preconceito é um juízo persistente adquirido anteriormente e que distorce a realidade. $O$ fato de ele serem falsos ou de segunda-mão representa empecilho para a construção do conhecimento e reconhecimento da verdade, já que cada conhecimento deve ser verificado racionalmente. Por este motivo, ansiavam por eliminar os preconceitos.

2) Serem falsos não é condição suficiente para o preconceito. Eles são ligados a afetos e atitudes. Essas características concedem-lhe persistência contra contradições. A ligação entre opinião e afetos não é ruim em si mesma. $O$ amor à verdade seria, segundo Locke, até mesmo necessária. A acusação iluminista a eles se funda na constatação de que a opinião é amada em vez da verdade, o que levaria à teimosia e à distorção da realidade.

3) O mundo é distorcido em razão da relação especial dos sentimentos que residem nos preconceitos. O mundo é reinterpretado porque a ligação relacional ao mundo é criada após o sentimento ser sentido. Isso quer dizer que o objeto da relação do sentimento no mundo lhe é acidental, de modo que o mundo não altera o sentimento. Mesmo assim essa relação é genuinamente sentida. E por isso, já que o sentimento não muda em razão dos fatos do mundo, são os fatos negados, pois o sentimento continua.

4) Um dos motivos pelos quais os iluministas se depararam com enorme desafio no combate aos preconceitos é por seus argumentos serem direcionados ao conhecimento da verdade. O desejo por trás da persistência dos preconceitos é outro que o pela verdade. Em razão do desconhecimento de que a ameaça é criada pelo sentimento anterior, sente-se como se os fatos do mundo fossem causadores dos preconceitos. Haja vista que o objetivo dos iluministas era combater os preconceitos voltando-se para a busca pela verdade, ou seja, o conhecimento de como o mundo é, eles poderiam no máximo combater as preconcepções. A diferença traçada por Allport entre preconcepção e preconceito lança uma importante luz no estudo sobre os preconceitos. O 'erro' dos iluministas foi o de tentar vencer os preconceitos quando eles atacavam 
meramente as suas sombras, ou seja: $O$ empecilho que representam ao conhecimento da 'verdade'.

\section{Referências}

ALLPORT, Gordon W. (1954): The Nature of Prejudice. New York: Anchor Books edition, 1958. 1-27.

BACON, Francis. Novum Organum. 1620. Disponível em: http://www.dominiopublico.gov.br/pesquisa/DetalheObraForm.do?select action $=\& \mathrm{co}$ obra $=2278$

CONDORCET, Marie Jean Antoine. (1794) Fortschritt des menschlichen Geistes. In: Was ist Aufklärung: Thesen, Definitionen, Dokumente. 9-18. Stuttgart: Reclam. 2010.

DESCARTES, Réne. Lés Meditations. Prémiere Méditation und Méditation Seconde. 1641. URL:

http://www.dominiopublico.gov.br/pesquisa/DetalheObraForm.do?select action $=\&$ co obra $=84335$ [Consultado em 20/12/2015]

DORSCHEL, Andreas. Nachdenken über Vorurteile. Hamburg: Felix Meiner Verlag, 2001.

FROMM, Erich. (1941) Die Furcht vor der Freiheit. Trad. Liselotte e Ernst Mickel. München: Deutscher Taschenbuch Verlag. 18. Edição, 2013. 137-151.

HEIDEGGER, Martin (1926) Sein und Zeit. Tübingen: Max Niemeyer Verlag, 2006.

HORKHEIMER, Max. Über das Vorurteil. Köln und Opladen: Westdeutscher Verlag, 1962.

KANT, Immanuel (1784) Beantwortung der Frage: Was ist Aufklärung?. In: Was ist Aufklärung: Thesen, Definitionen, Dokumente. 9-18. Stuttgart: Reclam. 2010.

Kritik der Urteilskraft. § 40. 1790. Disponível em:

https://korpora.zim.uni-duisburg-essen.de/Kant/aa05/293.html Acesso em: 20/12/2015. 
KLEG, Milton. Hate, Prejudice and Racism. Albany: State University of New York Press, 1993. 113-134.

LOCKE, John (1706) Conduct of Understanding. Section X - XII. London: Oxford University press Warehouse, 1881. 29 - 36. Disponível em: https://archive.org/stream/lockesconductofu00lock\#page/28/mode/2up Acesso em: 18/12/2015.

Disponível em:

An Essay Concerning Human Understanding. Chapter XIX. 1689. http://enlightenment.supersaturated.com/essays/text/johnlocke/essay/BOOKIVC hapterXIX.html

\author{
MORANA, Cyril; OUDIN, Éric (2010) Petit philosophie des grandes idées: La \\ Liberté. Paris: Groupe Eyrolles.
}

THOMASIUS, Christian. (1691) Der richtige Gebrauch der Vernunft. In: Was ist Aufklärung: Thesen, Definitionen, Dokumente. 9-18. Stuttgart: Reclam. 2010.

\footnotetext{
1 "Opinião ou ideia, juízo que se faz de alguém ou de alguma coisa"; "conceito", in Dicionário Priberam da Língua Portuguesa [em linha], 2008-2013, http://www.priberam.pt/dlpo/conceito [consultado em 27-042016].

2 Expressão na versão utilizada: Feinde der Vernunft und die Unterdrücker von Freiheit

${ }^{3}$ Gostaria ainda de ressaltar que, apesar das muitas críticas que podem ser feitas a esses autores, como por exemplo, que a conclusão cartesiana deveria ser de que "algo pensa" e não de que é um "eu" quem pensa, ou de que ele não teria discutido a questão do que é pensar e se levasse mesmo adiante sua dúvida metódica não seria capaz de fundar qualquer conhecimento; ou a crítica ao Selbstdenken kantiano, de que todo pensar é pensar por si, mesmo que se adote as conclusões dos outros. Tampouco me ocuparei das críticas aos conceitos de verdade, razão... Estas críticas não são aqui abordadas, pois o objetivo é captar como esses autores pensavam o preconceito, para o que é preciso compreender as relações dentro de seus próprios sistemas.

${ }^{4}$ Texto no original: For when a man says he sees or feels, nobody can deny him that he does so.

5 Texto no original: Die Rationalisierungen sind kein geeignetes Mittel, zur Wirklichkeit vorzustoßen, sondern nur post factum ein Versuch, die eigenen Wünsche mit der vorhandenen Wirklichkeit in Einklang zu bringen ${ }^{6}$ Texto no original: Thus the difference between ordinary prejudgments and prejudice is that one can discuss and rectify a prejudgment without emotional resistance.

7 Texto no original: Nicht wird etwa zunächst ein zukünftiges Übel (malum futurum) festgestellt und dann gefürchtet. Aber auch das Fürchten konstatiert nicht erst das Herannahende, sondern entdeckt es zuvor in seiner Furchtbarkeit. Und fürchtend kann dann die Furcht sich, ausdrücklich hinsehend, das Furchtbare »klar machen «. Die Umsicht sieht das Furchtbare, weil sie in der Befindlichkeit der Furcht ist.

8 Texto no original: Gegen die starren Vorurteile zu argumentieren, ist eitel.
} 